Case Report

\title{
Hypodontia With Class I Malloclusion and Maxillary Diastema
}

\author{
Bunga Fatimah, I Gusti Aju Wahju Ardani \\ Department of Orthodontics, Faculty of Dental medicine \\ University of Airlangga \\ Surabaya-Indonesia
}

\begin{abstract}
Background: Dental agenesis is a term that refers to the absence of one or more teeth, and hypodontia refers to a severe type of tooth agenesis involving less than six or more than one congenitally missing teeth, excluding the third molars. Purpose: This aimed to report the correction of overbite by using intrusion archwires. Case: A 20-year-old female patient had class I malocclusion and deep overbite, incisor retroclination, mild mandibular crowding and agenesis of 12, 13, 14, 15, and 24. Case management: The case was treated with non-extraction using 0.022 pre-adjusted technique to level and unravel using intrusion archwires to correct the deep overbite. Conclusion: The 17-month treatment resulted in a corrected overbite, good occlusion, and good facial aesthetics.
\end{abstract}

Keywords: Agenesis, deep overbite, hypodontia.

Correspondence: I Gusti Aju Wahju Ardani, Department of Orthodontics, Faculty of Dental Medicine Universitas Airlangga, J1. Prof. Dr. Moestopo No.47 Surabaya 60132 - Indonesia, Telp (031)5030255 Email: wahju_ardani@fkg.unair.ac.id

\section{INTRODUCTION}

Dental agenesis is one of the most common developmental disorders and is indicated with the absence of one or more than one tooth. Dental agenesis can affect both primary and permanent teeth. The majority of case reports showed that dental agenesis is mostly caused by genetic and molecular factors. ${ }^{(1)}$ The incidence of agenesis varies from 1.6 to $9.6 \%$, except for the loss of third molars, which occurs in $20 \%$ of the population. ${ }^{(2,3)}$ Evaluation study of permanent dental agenesis can be performed by clinical examination and radiographic evaluation of the oral cavity. ${ }^{(4)}$

Dental agenesis is classified based on the number of missing teeth which are called hypodontia or oligodontia. The term hypodontia is used if one to five teeth are lost, excluding the third molar. If six or more teeth are lost, excluding the third molar, this condition is categorized oligodontia. Anodontia, which indicates all teeth lost, is very rare. Those definitions have been widely used in scientific literature. ${ }^{(5)}$

Hypodontia, loss of six teeth or less has been reported as the most common dental anomaly that can affect the aesthetics and dental function. Environmental and genetic factors contribute to the occurrence of hypodontia. Infections, trauma, and drugs, and genes associated with certain syndromes can promote hypodontia as well. Children are more vulnerable than adolescents.
Radiographic examination is needed to classify the severity of hypodontia. It can be categorized as mild should there be one to three teeth that are progressively missing, medium if four to six teeth are progressively missing, and severe if more than six missing teeth. ${ }^{(5)}$ Congenital tooth lost can cause diastema and tooth tilting. It can also cause aesthetic problems, especially in the event of loss of lateral incisor. $^{(6,7)}$

The lower second premolar agenesis is generally associated with the persistence of the primary lower second molar. In the case of malocclusion with lower second premolar agenesis without crowding, and the primary second molars are in good condition (no caries and root resorption), the primary second molar can be maintained in the arch. Maintaining these teeth can prevent space closure without tipping and periodontal problems. Physiological resorption of primary second molars without the presence of a second premolar occurs at an average age of 22 years old. ${ }^{(8)}$

However, maintaining primary second molars can cause an imbalance in tooth size due to different mesiodistal crown size. The crown size difference between primary second molar and second premolars was approximately 1.5-2 $\mathrm{mm}$ that the interdigitation was not accurate. The primary second molars are wider than premolars. Thus, reducing the mesiodistal width of the primary second molar to $7 \mathrm{~mm}$ was recommended. But, the reduction in crown width of the 
primary second molar was limited due to root divergence. In the case of infraclusion primary second molars, the composite build-up is indicated to prevent supraclusion of opposing teeth and tipping of the first molar. ${ }^{(8)}$

If a removable denture or implant is planned to maintain the space of agenesis, the orthodontist has to prepare the space for the period of mix dentition and create a space. The orthodontist will collaborate with a prosthodontist to decide the best prostheses for the patient with agenesis. An implant is usually selected when the growth of the alveolar process has stopped. The preparation of the supporting tooth in the mix dentition period needs to be postponed if the pulp size is wide. Space maintenance can be done before the prostheses. In this case, the primary second molars could be the ideal space maintainer as it maintains space and prevents alveolar bone loss. Other alternative treatments were autotransplantation of the third molars and premolars. ${ }^{(9)}$

This paper aimed to report the management of agenesis by keeping the primary teeth to maintain the space, correct the overbite, and achieve good facial aesthetic using intrusion arch wires.

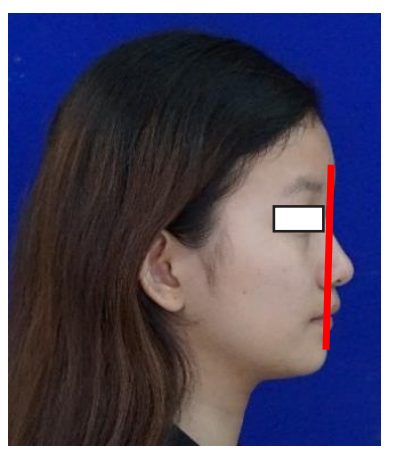

Figure 1. Extraoral facial profil pre treatment, straight profile

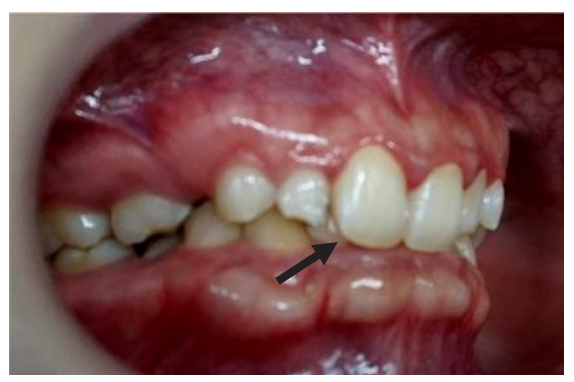

Figure 2. Intraoral pre treatment, deep over bite

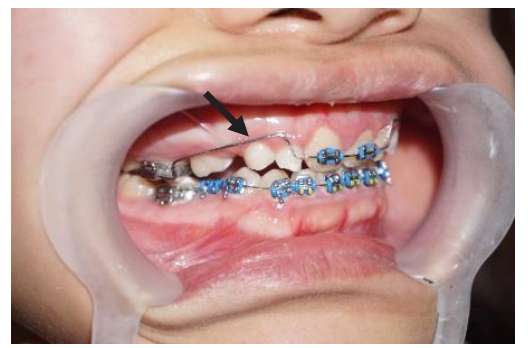

Figure 5. Intrussion arch wires

\section{CASE}

Twenty years old female patients visited the orthodontic clinic of Universitas Airlangga Dental Hospital with upper diastema, crowding of lower teeth, and deep overbite. An extraoral examination (Figure 1) showed a straight facial profile and mesocephalic head.

An intraoral examination showed a normal palate, low caries score, and normal tongue size. Class I molar relationship, class I canine relationship on the right side, and edge to edge canine relationships on the left side. The overbite was $5 \mathrm{~mm}$, the overjet was $1 \mathrm{~mm}$, and upper and lower incisive retroclination were found (Figure 2).

The panoramic examination (Figure 3) showed dental agenesis of $12,13,14,15$, and 24 . The results of cephalometric analysis (Figure 4) showed the relationship of class I malocclusion (ANB $=2^{0}$ ) with normal maxilla $\left(\mathrm{SNA}=80^{\circ}\right)$ and normal mandible $\left(\mathrm{SNB}=78^{\circ}\right)$. The angle of the upper incisor to SN line was 107 (retrusion of maxillary incisor ), the angle of lower incisor to GoGn was 80 (retrusion of mandibular incisor). The position of

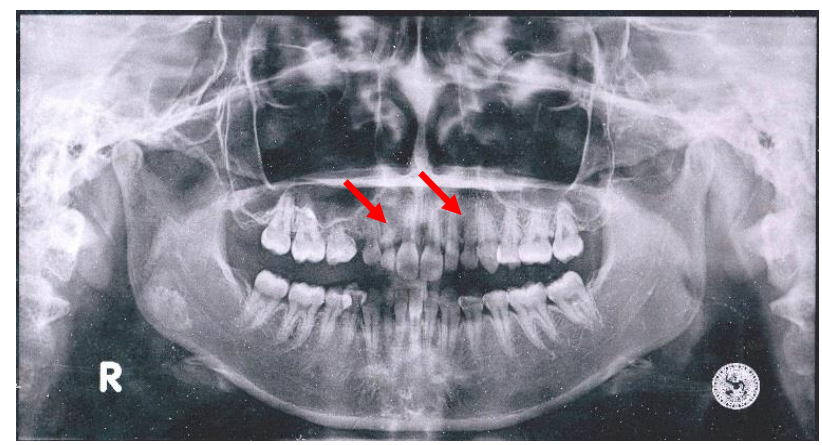

Figure 3. Panoramic pre treatment, agenesis of 12, 13, 14, 15, 24

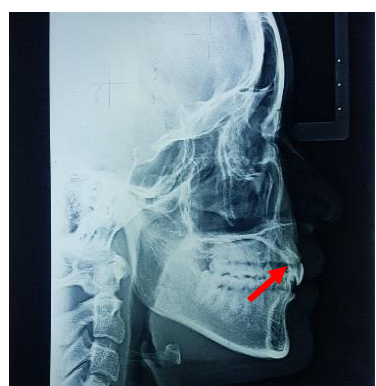

Figure 4. Cephalometric pre treatment, deep overbite

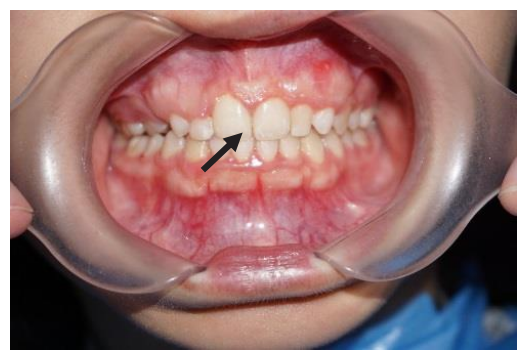

Figure 6. Intraoral post treatment, normal overbite 
the upper lip was $2 \mathrm{~mm}$ behind the $\mathrm{E}$ line, and the lower lip was $2 \mathrm{~mm}$ behind the E line. Vertical dysplasia on the middle face was $46 \%$, and on the lower face was $54 \%$ (the length of the lower face was less than normal).

The possible etiology of malocclusion, in this case, was heredity as the mother had upper diastema and some primary teeth too. The goals of treatment were to correct the deep overbite, overjet, dental malposition, and vertical dimensions.

The agenesis treatment was selected without extracting the primary teeth but rather maintaining the primary teeth. Treatment of the maxilla for intruding the right and left upper central incisor and extruding right and left maxillary molar teeth. The brackets were placed on tooth 16, 11, 21, and 26 (with the two by four methods with pre-adjusted brackets). Intrusion archwires were made using 016 x 022 stainless steel wire. Activation of intrusion archwires was performed by bending the back wire (molar towards the gingival of $15^{\circ}$ ) so that when the wire is installed, it would give intrusion effects on the anterior teeth and extruding the posterior teeth (Figure 5).

The anterior teeth intrusion and posterior teeth extrusion to obtain a normal overbite $(2 \mathrm{~mm})$ was done in 6 months. Once a normal overbite achieved, the intrusion archwires

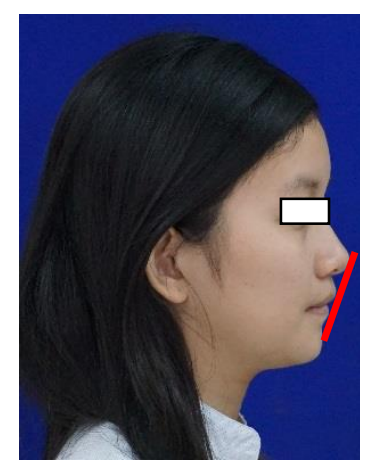

Figure 7. Extraoral facial profil post treatment, normal E line were no longer activated (passive). The mandibular bracket was placed in the 3 rd month with a posterior bite raiser to maintain the anterior overbite (Figure 5). The leveling of the lower teeth was done by using Ni-Ti, 0.012, 0.014, 0.016, $0.016 \times 016 \mathrm{Ni}-\mathrm{Ti}$, and $0.016 \times 0.022$ for 6 months.

Treatment was completed after 17 months, obtaining class I right and left molar relationships, class I right canine relations, and left canine cups to cups. Once the overjet and the ideal overbite $(2 \mathrm{~mm})$ were achieved (Figure 6$)$, the extraoral facial profile post-treatment showed no change in the $\mathrm{E}$ line, the upper lip was $2 \mathrm{~mm}$ behind the $\mathrm{E}$ line, and the lower lip was $2 \mathrm{~mm}$ behind $\mathrm{E}$ line (Figure 7).

Post-treatment vertical dysplasia was $45 \%$ on the middle face and $55 \%$ on the lower face. The lower and upper face lengths were normal with intrusion of the central incisor and extrusion of the maxillary molar (Figure 8).

\section{DISCUSSION}

Two basic treatment options for patients with agenesis are space closing and space maintaining. ${ }^{(10)}$ The treatment for this case, hypodontia with five teeth agenesis $(12,13,14$, 15 , and 24), was space maintenance without primary tooth

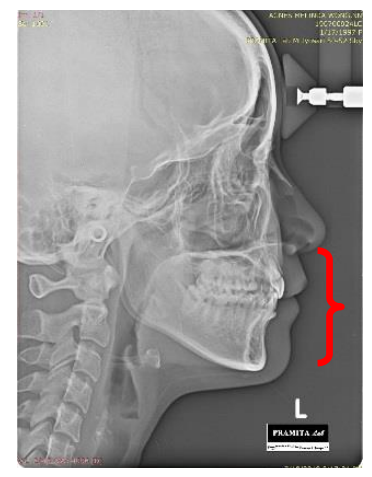

Figure 8. Cephalometric post treatment, normal lower facial height.

Table 1. Pre-treatment and post-treatment cephalometric analysis

\begin{tabular}{lccc}
\hline Parameter & Normal score & Pre-treatment & Post-treatment \\
\hline SNA (angle) & $79-89$ & 80 & 80 \\
SNB (angle) & $74-89$ & 78 & 78 \\
ANB (angle) & $0-4$ & 2 & 2 \\
Occl to S-N (angle) & $5-30$ & 21 & 22 \\
GoGn to S-N (angle) & $20-40$ & 36 & 37 \\
Upper incisor to SN (angle) & $98-123$ & 97 & 103 \\
Upper incisor to maxilla (angle) & $104-125$ & 99 & 104 \\
Upper incisor to FH & $101-125$ & 97 & 101 \\
Maxilla to mandible & $24-32$ & 28 & 29 \\
Lower incisor to GoGn (angle) & $80-110$ & 80 & 82 \\
\hline
\end{tabular}


extraction. The space maintenance with the presence of primary teeth $(55,53,52$, and 64$)$ will be followed with dental prostheses. The primary teeth were in good prognosis, particularly if the primary teeth are maintained. As the malocclusion with lower second premolar agenesis without crowding and primary second molar were in good condition (no caries and root resorption), the tooth might remain in the dental arch. In addition, physiological resorption of primary second molars without the presence of a second premolar occurs at an average age of 22. ${ }^{(3)}$

The patient was 20 years old, thus, the physiological resorption of primary teeth without new permanent teeth was found. This was supported by the presence of primary teeth in the patient's mother who has survived to the present age (45 years). So, primary teeth were kept to maintain the space and maintain dental arches.

The treatment goal was to improve the mastication and speech function, maintain vertical dimensions, and restore the aesthetic appearance. In this case, the treatment was carried out by intruding the upper central incisor and extruding the upper molar. This was to improve the patient's aesthetic by adding a vertical dimension of the lower facial height to normal. The overjet and overbite were normal (2 mm), which could restore mastication and aesthetic functions.

Active treatment was completed in the 17 th month. The retainer was installed to maintain periodontal tissue stabilization and to prevent relapse. The retainer used was Hawley retainer. The correction of the maxillary incisor retrusion was performed with a maxillary plane $\left(94^{\circ}\right)$, horizontal Frankfurt plane $\left(101^{\circ}\right)$, and the pre-treatment SN line $\left(107^{\circ}\right)$ which became normal at the end of treatment (Table 1). After treatment, the angle of SNB, SNA, and ANB remained in a good score. The vertical dysplasia became normal with the addition of lower face height due to the extrusion of posterior teeth.

In lateral cephalometric superimposition, the upper lip and lower lip were normal; the upper lip was $2 \mathrm{~mm}$ behind the E-line, and the lower lip was $2 \mathrm{~mm}$ behind the E-line. Orthodontic treatment for teeth abnormalities shall not be generalized because there are many variations. Orthodontic treatment plans for permanent dental agenesis are space closure and space maintenance. In space maintenance, it is followed by making a prosthesis. If possible, use primary teeth instead of permanent teeth.
This presented hypodontia case treatment without extraction, the and primary teeth were kept to maintain space using intrusion archwires. This was possible because the patient's primary teeth were in good condition. There was mild root resorption so that the primary teeth could still be maintained until the next treatment, making prostheses. The overbite was normal, retroclination of upper and lower incisors. Normal overjet and overbite to improve the function and achieve good aesthetic.

\section{REFERENCES}

1. Ritwik P, Patterson KK. Diagnosis of tooth agenesis in childhood and risk for neoplasms in adulthood. Ochsner J. 2018;18(4):345-50.

2. Sharma VK, Kumar S, Yadav K, Chaturvedi D Abd TP. Agenesis of Lateral Incisors: Treatment Options and Case Report. 2018;08(2):155-9. Available from: https://www.ijsr. in/upload/785337036Chapter_29.pdf

3. Watted N, Borbély P, Watted A, Nidal G, Azzaldeen A, AbuHussein M. Multidisciplinary approach in the rehabilitation of congenitally missing lateral incisivus: a new trend in daily practice. Oral Heal Care. 2016;1(1).

4. Medio M, Popelut A, De La Dure Molla M. Management of mandibular second premolar agenesis. J Dentofac Anomalies Orthod. 2015;18(1):105.

5. Al-Ani AH, Antoun JS, Thomson WM, Merriman TR, Farella M. Hypodontia: An Update on Its Etiology, Classification, and Clinical Management. Biomed Res Int. 2017.

6. Silveira GS, Mucha JN. Agenesis of Maxillary Lateral Incisor: Treatment Involves Much More Than Just Canine Guidance. Open Dent J. 2016;10(1):19-27.

7. Arandi NZ, Mustafa S. Maxillary lateral incisor agenesis; a retrospective cross-sectional study. Saudi Dent J. 2018;30(2):155-60.

8. Jha P, Jha M. Management of congenitally missing second premolars in a growing child. J Conserv Dent. 2012;15(2):187-90.

9. Anandita R, Widayati R. INSISIF LATERAL ATAS DAN PREMOLAR DUA BAWAH PADA PERIODE GIGI BERCAMPUR Pendahuluan Tinjauan Pustaka. Indones J Dent [Internet]. 2009;16(4):18-24. Available from: http:// jdentistry.ui.ac.id/index.php/JDI/article/download/18/15

10. Pini NIP, Marchi LM De, Pascotto RC. Congenitally Missing Maxillary Lateral Incisor: Update on the Functional and Esthetic Parameters of Patients Treated with Implants or Space Closure and Teeth Recontouring. Open Dent J. 2015;8(1):289-94. 